\title{
Propylthiouracil-induced hypothyroidism delays apoptosis during the first wave of spermatogenesis
}

\author{
Doris Silva, Carlos Lizama, Verónica Tapia ${ }^{1}$ and Ricardo D. Moreno², \\ Departamento de Ciencias Fisiológicas, Facultad de Ciencias Biológicas, Pontificia Universidad Católica de Chile, ${ }^{1}$ Hospital Clínico Universidad de Chile
}

\begin{abstract}
Mammalian germ cell apoptosis plays a key role in controlling the correct number of germ cells supported by Sertoli cells during the first wave of spermatogenesis in mammalian puberty. However, little is known about hormonal factors that could influence the rate of germ cell apoptosis during puberty or adulthood. In this work we evaluate germ cell apoptosis under hypothyroidism induced by goitrogen propylthiouracil (PTU) during the first wave of spermatogenesis. Neonatally administered PTU promoted a delay in the differentiation of Sertoli cells as evaluated by the expression of clusterin using immunohistochemistry and RT-PCR. Clusterin had different expression levels in control and PTU-treated animals, but under both conditions the highest levels were found in 35-day-old rats. In addition, clusterin displayed a cytoplasmic localization in control testes, but appeared located in the nucleus in PTU-treated animals. The wave of apoptosis (determined by caspase activity and quantification of apoptotic cells) characteristic of the first round of spermatogenesis was delayed by at least 10 days in these animals. The expression levels of proapoptotic genes like BAX or BAD were different between control and PTU-treated rats; although in both groups the highest level was found at the same age (days). Thus our results indicate that the characteristic pubertal apoptotic wave during rat spermatogenesis is delayed in neonatal hypothyroid rats.
\end{abstract}

Key words: Testis, spermatocyte, Sertoli cell, caspase, apoptosis, thyroid.

\section{INTRODUCTION}

The Sertoli cell is a key player in spermatogenesis since it provides nutrients, trophic signals, endocrine regulation, mechanical support and is also believed to control germ cell homeostasis by regulating the number of differentiating cells executing apoptosis (Sharpe, 1994). In mice and rats, Sertoli cells begin to proliferate at birth, but stop dividing around postnatal day 15, which is accompanied by expression of specific markers, such as clusterin (McKinnell and Sharpe, 1997; Plotton et al., 2005). This differentiation involves the induction of the cyclin-dependent kinase inhibitor p27kip1 by the thyroid hormone (T3) (Holsberger et al., 2005a; Holsberger et al., 2003). Hypothyroidism in the neonatal rat impairs testicular growth, germ cell maturation, seminiferous tubule formation and other differentiation processes (De Franca et al., 1995; Maran et al., 2001). Despite the inhibitory effects induced by goitrogen 6-propyl-2-thiouracil (PTU) when administered from birth to postnatal day 25, a dramatic recovery of thyroid hormone levels to the euthyroid state after postnatal day 45 has been observed (Cooke et al., 1991). Once adult, these treated animals experience an increase in testis size and daily sperm production of $80 \%$ and $140 \%$ respectively, compared to control animals. Thus after recovery from hypothyroidism, these animals have a larger adult Sertoli cell population, which leads to increased numbers of germ cells through an unknown mechanism (Cook et al., 2005).

Conversely, rats treated with the thyroid hormone T3 express a premature cessation of Sertoli cell proliferation and a stimulation of maturation events such as seminiferous tubule canalization, and a subsequent decrease in sperm production during adulthood, suggesting that T3 has direct effects on Sertoli cells (Holsberger and Cooke, 2005). Overall, these data support the idea that thyroid hormone (T3) plays a role in Sertoli cell differentiation.

Apoptosis is a particular type of programmed cell death that is characterized by the expression of pro-apoptotic genes and the activation of a family of cystein-proteases called caspases (Taylor et al., 2008). Generally speaking two pathways, intrinsic and extrinsic, are involved in the apoptosis process in a variety of cell systems, including mammalian germ cells. The intrinsic pathway of apoptosis involves the release of cytochrome $\mathrm{C}$ from mitochondria into the cytosol, where it binds to apoptotic protease activating factor 1 (Apaf 1) and dATP, resulting in the activation of initiator caspase 9 and the subsequent proteolytic activation of caspases 3, 6, and 7 (Taylor et al., 2008). Members of the BCL2 family of proteins play a major role in controlling this mitochondriadependent apoptotic pathway, with proteins such as BAX or BAD functioning as inducers of apoptosis and proteins such as BCL2 as suppressors of cell death (Youle and Strasser, 2008). p53 is a well-characterized tumor suppressor protein, actively involved in the mitochondrial pathway of apoptosis by either inducing transcription of pro-apoptotic genes or its direct effects on mitochondrial membranes (Pietsch et al., 2008). The extrinsic pathway of apoptosis involves the binding of a death receptor (such as FAS) to its ligand (Peter and Krammer, 2003), FASL. Binding of FASL to FAS induces the trimerization of FAS receptors, leading to the activation of initiator caspases 8 or 10 , which in turn activate the effector or executioner caspases 3,6 , and 7 , resulting in cellular disassembly.

During rat and mouse puberty a massive wave of apoptosis occurs around the third week, characterized by activation of caspases-3,-8 and -9 , and an upregulation of proapoptotic genes such as FAS, BAX and PUMA, suggesting the participation of the extrinsic and intrinsic pathway during 
germ cell depletion (Billig et al., 1996; Codelia et al., 2008; Lizama et al., 2007; Moreno et al., 2006; Rodríguez et al., 1997). It has been hypothesized that germ cells undergoing apoptosis are those supernumerary cells that cannot establish a proper functional interaction with the Sertoli cells. In this context, we wanted to test the hypothesis that the signal inducing germ cell apoptosis is germ cell intrinsic or germ cell extrinsic. In other words, if the timing of germ cell apoptosis during the first wave of spermatogenesis depends only on germ cells or if it depends on Sertoli cell-derived signals. Thus, using a hypothyroidism model where Sertoli cell differentiation is delayed, we hypothesized that if apoptosis depends on the intrinsic properties of germ cells, we should not observe any change in the timing of germ cell apoptosis during the first wave of spermatogenesis. On the other hand, if germ cell apoptosis depends on Sertoli cell differentiation, a difference in the timing of the first wave should be observed.

\section{MATERIALS AND METHODS}

Animals and treatment

Male Sprague-Dawley rats were acquired from the Animal Facility of our faculty. The rats were housed under a 12L:12D cycle, with water and rat chow being provided ad libitum. They were killed by cervical dislocation. Investigations were conducted in accordance with the rules laid down by the Consortium for Developing a Guide for the Care and Use of Agricultural Animals in Agricultural Research and Teaching and by the National Research Council. All animal protocols were endorsed by the Chilean National Fund of Science and Technology (FONDECYT). Male rats were made hypothyroid by adding $0.01 \%$ PTU $(\mathrm{w} / \mathrm{v})$ to the mother's drinking water from birth until Day 25 (Cooke et al., 1991; De Franca et al., 1995). PTU ingested by the mother passes through the milk into the pups, where it causes severe hypothyroidism.

\section{Chemicals and antibodies}

Unless otherwise stated, all chemicals were purchased from Sigma Company (St Louis, MO). The antibody against clusterin (sc-1023) was purchased from Santa Cruz Biotechnology (Santa Cruz, CA). Caspase-8 (z-IETD-pNA), caspase-9 (z-LEHD-pNA), and caspase-3 (z-DEVD-pNA) substrates were purchased from Merck (Darmstat, Germany). Anti-rabbit UltraVision Detection Systems were obtained from LabVision (Fremont, CA).

\section{Thyroid hormone determination}

T3 and T4 hormone determinations were made in $400 \mathrm{ml}$ of 25-day-old rat serum with a solid-phase competitive chemiluminescent enzyme immunoassay (Siemens/DPC, Deerfield, IL) according to the manufacturer's specifications. Chemiluminescence was quantified in an Immulite 1000 (System Siemens Healthcare Diagnostics, Deerfield, IL).

\section{Morphometric measures}

Morphometric measurements were performed in crosssections of paraffin-embedded testes fixed in Bouin's solution. Sections were counterstained with peryodic acid-Schiff (PAS) and hematoxylin for the assessment of germ cell apoptosis. Seminiferous tubule area and diameter were determined using the program Image Tool 2.0, a free image processing and analysis program for Microsoft Windows developed by C. D. Wilcox, S. B. Dove, W. D. McDavid and D. B. Greer (Department of Dental Diagnostic Science at the University of Texas Health Science Center, San Antonio, Texas). The area and diameter were determined using 100 seminiferous tubules per rat per age (a total of 3 rats, 300 tubules) using the tools provided by the program. The values are given as the mean \pm standard deviation (S.D.). Sertoli cell nuclei are easily identified by their characteristic shape and localization along the seminiferous tubule. Sertoli cell number was determined by counting the Sertoli cell nuclei at each age in 100 seminiferous tubules per rat per age (a total of 3 rats, 300 tubules). The values are given as the mean \pm standard deviation (S.D.).

\section{RT-PCR}

The levels of mRNAs were evaluated in a germ cell suspension obtained from seminiferous tubules, as described below. This procedure allowed us to determine the mRNA only in cells inside the seminiferous tubules, avoiding the interference of other cell types, such as Leydig cells, macrophages or cells from blood vessels. Total RNA was isolated using Trizol-Reagent (Invitrogen, Carlsbad, CA). First, complementary DNA was made using $5 \mu \mathrm{g}$ total RNA in the presence of Superscript III reverse Transcriptase (In Vitrogen, Carlsbad, CA) and random primers. After the RT reaction $51 \mu \mathrm{l}$ of the incubation mixture was used as a template for the subsequent PCR reaction. Several primer sets were used to obtain the PCR products of clusterin forward 5'-CGGAAGTGTGTAACGAGACCA-3': Reverse 5'-ATCTTCAGGCATCCTGTGGAG-3': p53 forward 5'-ATATGAGCATCGAGCTCCCTCT-3': reverse 5'-CACAACTGCACAGGGCATGT-3', BAX forward 5'-AGACAGGGGCCTTTTTGTTAC -3' reverse 5'-GAGGACTCCAGCCACAAAGAT -3'; BAD forward 5'-GGGAGAAGAGCTGACG -3' reverse 5'-GTCTCGGTTTACCAGGAC - 3' and GAPDH forward 5'-ACCACAGTCCATGCCATCAC -3': reverse 5' -TCCACCACCCTGTTGCTGTA - $3^{\prime}$ The reaction was initiated at $94{ }^{\circ} \mathrm{C}$ for $1 \mathrm{~min}$, followed by $94^{\circ} \mathrm{C}$ for $30 \mathrm{sec}, 60^{\circ} \mathrm{C}$ for $45 \mathrm{sec}$, and $72^{\circ} \mathrm{C}$ for $1 \mathrm{~min}$ for 30 cycles, and a final extension at 72 ${ }^{\circ} \mathrm{C}$ for $5 \mathrm{~min}$. Aliquots of the PCR products were run in a $1 \%$ agarose gel and then stained with $0.1 \mathrm{~g} / \mathrm{ml}$ ethidium bromide. Digital pictures were taken using a NIKON camera (Coolpix 4500, Japan) and the intensity of each band (number of pixels) was calculated using the Program Image J v 1.41, a public domain, Java-based image processing program developed at the National Institute of Health (http://rsb.info.nih.gov/ij/). The values are given in arbitrary units (UA) that represent the ratio between the number of pixels between the band of interest and that of GADPH, as a loading control.

\section{Immunohistochemistry}

Clusterin expression and localization were assayed in paraffinembedded cross sections of rat testes fixed in Bouin's solution. The samples were first treated with $3 \% \mathrm{H} 2 \mathrm{O} 2$ for 5 min, then, to prevent unspecific binding, a standard protein block system (Ultra V block, LabVision, Freemont, VA) was applied for 5 
min. Primary antibody (rabbit polyclonal) against Clusterin (Santa Cruz Biotechnologies, SantaCruz, CA) was applied at a concentration of $2 \mathrm{mg} / \mathrm{ml}$ and incubated overnight at $4^{\circ} \mathrm{C}$ in a humidified chamber after being washed twice for 5 min in a Tris- $\mathrm{HCl}$ buffer, $\mathrm{pH} 7.6$ with $0.3 \mathrm{M} \mathrm{NaCl}$ and $0.1 \%$ Tween 20. Biotinylated secondary antibody donkey anti-rabbit $(1 \mathrm{mg} / \mathrm{ml})$, streptavidin-biotinylated-peroxidase complex, amplification reagent (biotinyl-tyramide) and peroxidaseconjugated streptavidin were applied step by step for 30 min each. Afterwards, incubation slides were washed twice in a buffer for $3 \mathrm{~min}$. Finally, substrate-chromogen solution consisting of concentrated Tris- $\mathrm{HCl}$ and $0.8 \% \mathrm{H}_{2} \mathrm{O}_{2}$ (substrate) and 3,3-diaminobenzidine tetrahydrochloride (DAB) solutions (chromogen) were applied for $5 \mathrm{~min}$ and washed off in distilled water. Samples were observed under a phase contrast microscope (Optiphot-2, Nikon, Japan) and photographed with a digital camera (CoolPix 4500, Nikon, Japan).

\section{Apoptosis evaluation}

The apoptotic index was calculated as the average number of apoptotic (pycnotic) cells per seminiferous tubule cross-section. Three testicular histological sections of the right testis were used (three rats, a total of 9 sections), and a minimum of 100 randomly selected tubules was counted in each tissue section (a total of 900 tubules were recorded per treatment). The data represent the mean $( \pm S D)$. We have previously shown that pycnotic germ cells express apoptotic markers such as active caspase-3 and stain positively for TUNEL (Codelia et al., 2010; Moreno et al., 2006).

\section{Seminiferous tubule cell isolation}

Briefly, testes from 15-45 day-old rats were dissected into a Petri dish with EKRB (enriched Krebs-Ringer bicarbonate) medium containing $120.1 \mathrm{mM} \mathrm{NaCl}, 4.8 \mathrm{mM} \mathrm{KCl}, 25.2 \mathrm{mM}$ $\mathrm{NaHCO}_{3}, 1.2 \mathrm{mM} \mathrm{KH} \mathrm{PO}_{4}(\mathrm{pH} 7.2), 1.2 \mathrm{mM} \mathrm{MgSO}{ }_{4} \times 7 \mathrm{H}_{2} \mathrm{O}$, $1.3 \mathrm{mM} \mathrm{CaCl}_{2}$, supplemented with $11.1 \mathrm{mM}$ glucose, $1 \mathrm{mM}$ glutamine, $10 \mathrm{ml} / \mathrm{L}$ MEM essential amino acid solution (GIBCO/Invitrogen, Carlsbad, CA), $10 \mathrm{ml} / 1$ BME nonessential amino acid solution (GIBCO/Invitrogen, Carlsbad, CA), 100 $\mathrm{mg} / \mathrm{ml}$ streptomycin, and $100 \mathrm{U} / \mathrm{ml}$ penicillin (K salt). Dry collagenase was added at a final concentration of $0.5 \mathrm{mg} / \mathrm{ml}$. The testes were then incubated for $15-45 \mathrm{~min}$ at $32^{\circ} \mathrm{C}$ with gentle stirring. Once the seminiferous tubules were dispersed in the medium, they were allowed to settle at the bottom of the dish, and the medium was aspirated and discarded. Germ and Sertoli cells were mechanically dissociated by aspirating the tubules with $18 \mathrm{G}$ and $20 \mathrm{G}$ syringes. This final cell suspension was used to determine caspase activity.

\section{Caspase activity measurement}

Caspase activity assays were performed using a germ cell suspension obtained from seminiferous tubules, as described above. Briefly, the cell suspension was homogenized in a buffer containing $1 \mathrm{M} \mathrm{NaCl}, 1 \mathrm{mM}$ EDTA, $10 \mathrm{mg} / \mathrm{ml}$ PMSF, $1 \%$ Triton X-100, $20 \mathrm{mM}$ Tris- $\mathrm{HCl} \mathrm{pH}$ 7.4. Caspase substrates were labelled with chromophore p-nitro aniline (pNA), which is released upon caspase cleavage, producing a yellow color, which is measured by a spectrophotometer at $405 \mathrm{~nm}$. The amount of product generated was calculated by extrapolation of a standard curve of free pNA. One international unit (IU) was defined as the amount of caspase hydrolyzing $1 \mathrm{mmol}$ of $\mathrm{pNA} / \mathrm{min}$ at $25 \mathrm{C}$. Results are expressed in units of enzyme per milligram of tissue (Units). The results are presented as the mean for six rats. Each determination was performed in six rats in triplicate.

\section{Statistical analysis}

Each experiment was conducted at least three times independently, unless clearly stated otherwise. In case the variance between groups was found to be similar, a oneway ANOVA was performed with a Bonferroni post-test to determine differences between groups. When the data was found to be non-parametric, a Kruskal-Wallis test was used. Dunn's multiple comparison tests were performed afterwards to determine differences between groups. If these tests were found to be at least $\mathrm{p}<0.05$, differences were considered statistically significant. Graphs show the mean of the experiments and the bars indicate the standard deviation of the mean (S.D.) (Sokal, 1995).

\section{RESULTS}

First, we set out to validate our experimental model and to characterize the phenotype of PTU-treated pubertal rats. To this end, we measured the levels of thyroid hormones in 25-day-old rats, the age at which the pup normally is weaned. Hormone T4 was not detectable in PTU-treated rats, while controls had $8.2 \pm 1.1 \mathrm{mg} / \mathrm{dl}(\mathrm{n}=6)$. Similarly, 25-day-old PTUtreated rats had undetectable levels of T3 while control rats had $230 \pm 12 \mathrm{ng} / \mathrm{dL}(\mathrm{n}=6)$. Thus hormone parameters are in accordance with neonatal hypothyroidism induced by PTU.

Histological examination of testes showed that the area and the diameter of PTU-treated seminiferous tubules were significantly smaller than controls in all studied ages (Fig. 1B, C). Sections of 25-day-old treated rats showed a clear decrease in the number of germ cells, compared to controls, and many tubules showed the lumen filled with clusters of spermatocytes (Fig. 1A). The few germ cells in the seminiferous epithelium were classified as spermatogonia and primary spermatocytes. Tubules of 35-day-old control rats showed a well-developed lumen and round and early elongating spermatids were the most advanced stages of germ cell differentiation observed. On the contrary, only a few seminiferous tubules of PTU-treated rats showed a clear lumen, suggesting a defect in Sertoli cell function. In addition, germ cells present in the seminiferous tubules were mainly spermatogonia and spermatocytes, and no round or elongating spermatids were observed at this age (Fig 1A). Seminiferous tubules of 45-day-old control rats showed a clear, well-developed epithelium exhibiting all stages of spermatogenesis commonly found in adult animals; spermatogonia, spermatocytes and late elongating spermatids (step 16, Fig. 1A). On the contrary, PTU-treated testes showed smaller tubules with fewer germ cells, and round spermatids were rarely observed.

Next we evaluated Sertoli cell differentiation using the expression levels of clusterin mRNA, a well-known differentiation marker of Sertoli cells. Clusterin mRNA levels in PTU-treated rats were significantly lower than in control in 15, 25 and 45-day-old rats, again with exception of 35-day- 
old rats (Fig. 2). In fact, clusterin mRNA was not detectable in the testes of PTU-treated 15-day-old rats. Despite the differences in mRNA levels, both control and PTU-treated testes showed the highest level of clusterin in 35-day-old rats. Immunolocalization of clusterin in Sertoli cells from 15-dayold control testes showed a strong nuclear/perinuclear signal, whereas in PTU-treated animals we did not observe any label within the seminiferous tubules, which is in accordance with the absence of mRNA levels found at this age (Fig 3). Sertoli cells displayed a cytoplasmic localization of clusterin in control rats of 25 and 35 days old, whereas PTU-treated animals had a clear nuclear/perinuclear localization, similar to that found in 15-day-old control testes (Fig 3). These results suggest that PTU promotes a change in clusterin expression levels and localization in Sertoli cells.

Thus, we were able to reproduce the phenotypical characteristics of neonatally PTU-treated rats. These results prompted us to ask whether other parameters of testis physiology, such as apoptosis or germ cell development, were also altered in PTU-treated rats.

\section{Apoptosis is delayed in hypothyroidic rats}

We evaluated apoptosis in histological sections of rat testes stained with hematoxylin and PAS at different ages in both control and PTU-treated animals. This method is based on the fact that germ cells in late stages of apoptosis become condensed and appear pycnotic (Moreno et al., 2006). In control rats, the highest apoptotic index was found in 25-day-old rats, all other values were significantly lower (Fig $4,{ }^{*} \mathrm{p}<0.05$ ). The apoptotic index of PTU-treated animals was significantly lower than controls in 25-day-old rats, and was similar to that observed in 15 -day-old rats (Fig. 4A, ${ }^{*} \mathrm{p}<0.05$ ). Apoptosis in PTU-treated rats increased with age and was significantly higher in 45-day-old rats than in 15 or 25-day-old rats (Fig 4A $\left.{ }^{*} \mathrm{p}<0.05\right)$. Quantification of apoptosis in adult animals (90-dayold rats) showed us that apoptosis in control and PTU-treated animals were similar (data not shown). Caspase activity measurements in control rats showed that caspase-3, -8 and -9 had maximum activity in 25-day-old rats, while values at other ages were significantly lower (Fig 4B, C and D, white bars).

A

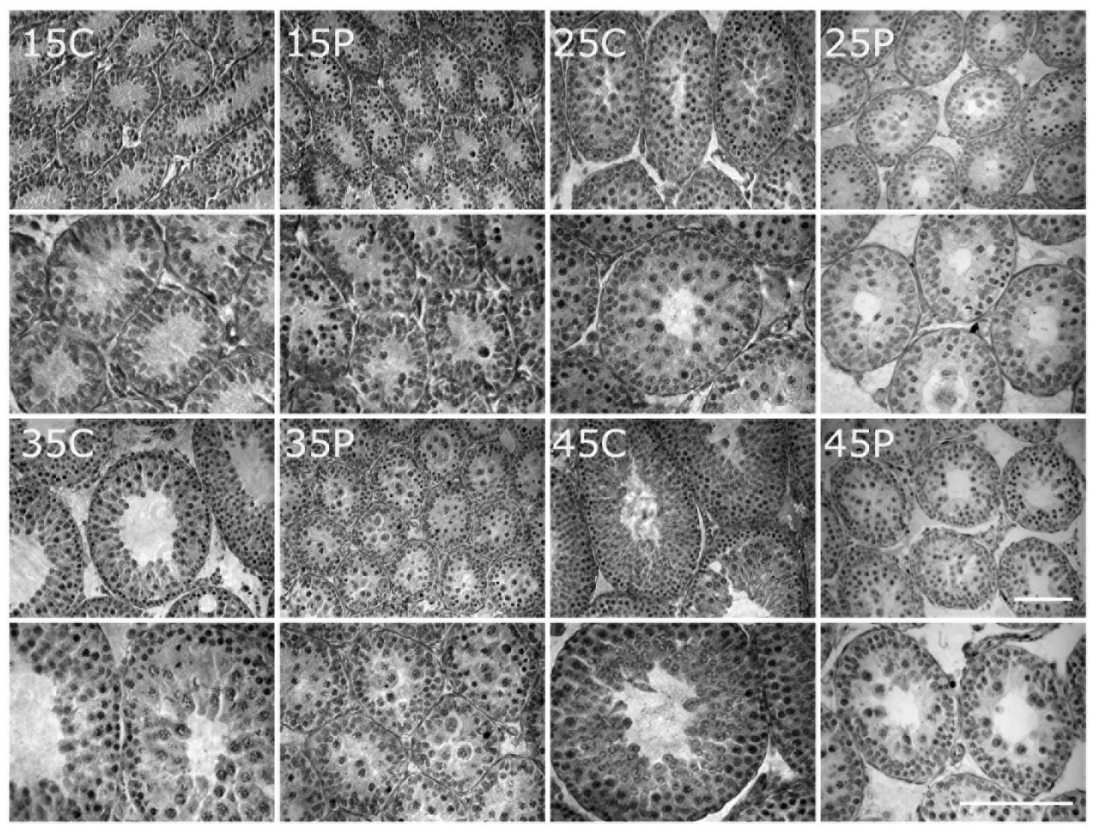

B

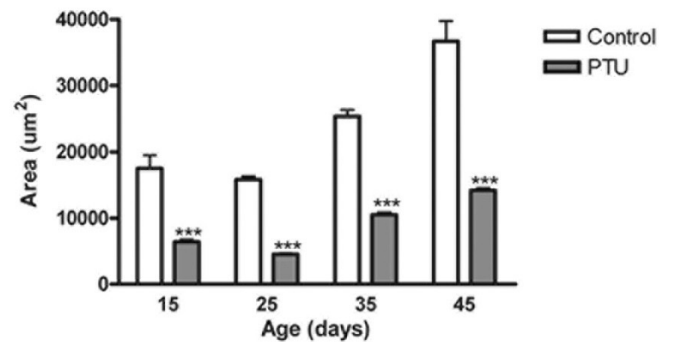

C

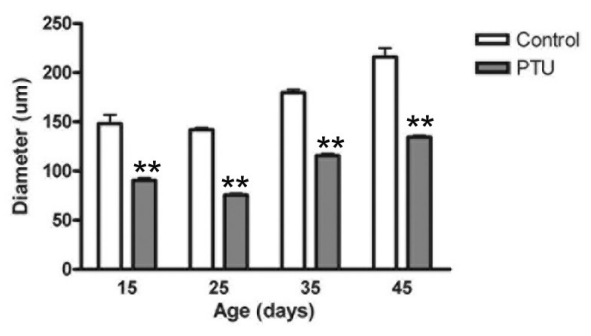

Figure 1: Hypothyroidism induces histological alterations in pubertal testes.

A) The figure shows hematoxylin-PAS staining of slides of testes from control and PTU-treated rats from 5 to 45 days old. Note that the number of cells inside the tubules is less in PTU-treated animals at all studied ages between 15 to 45 days. Observe that tubules of the 45-day-old rat are devoid of spermatids. The area (B) and diameter (C) of seminiferous tubules from PTU-treated rats are significantly less than controls. ${ }^{* *} \mathrm{p}<0.01 ;{ }^{* * *} \mathrm{p}<0.001, \mathrm{n}=3$. 
A

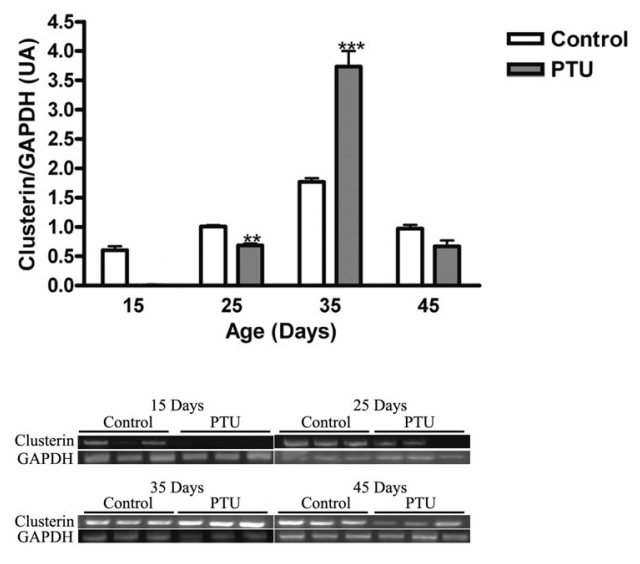

B

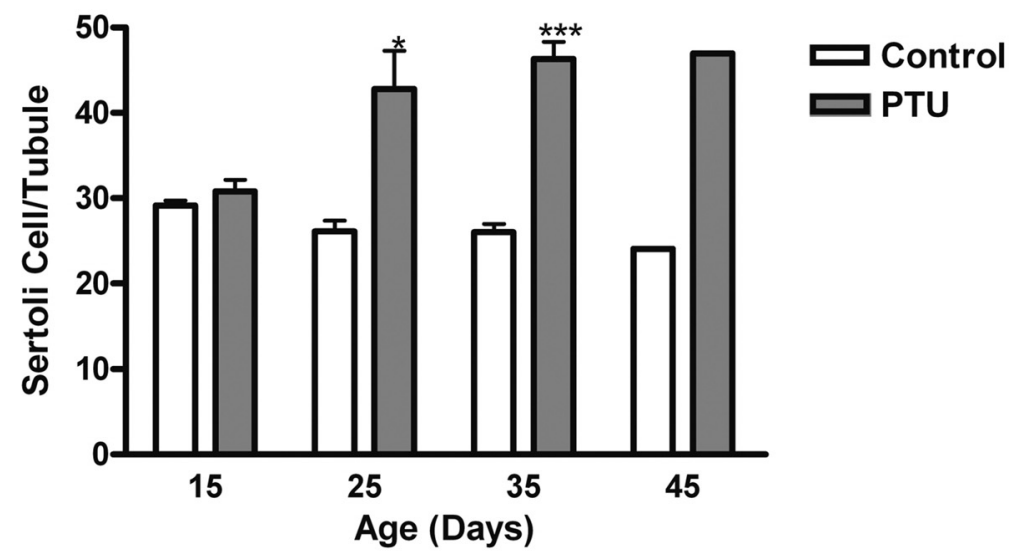

Figure 2: Propylthiouracil induces a delay in clusterin expression.

A) Clusterin mRNA levels were measured at different ages and levels were quantified in relation to the housekeeping gene GADPH. In the gel each lane represents a different experiment. Clusterin in PTU-treated testes from 15-day-old rats was not detectable. B) Sertoli cell nuclei were counted in transversal sections of control (white bars) and PTU-treated testes (gray bars). Each bar represents 300 tubules from three different rats $\left(\mathrm{n}=3,{ }^{*} \mathrm{p}<0.05:{ }^{* *} \mathrm{p}<0.01 ;{ }^{* * *} \mathrm{p}<0.001\right)$.

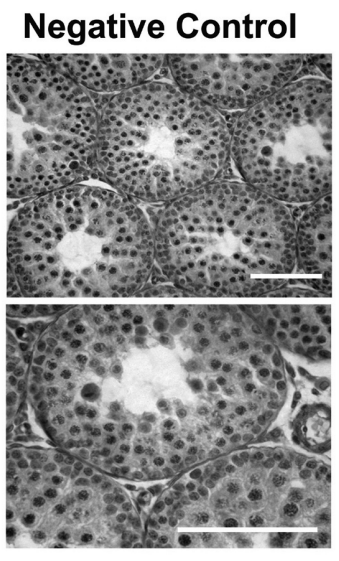

25 days

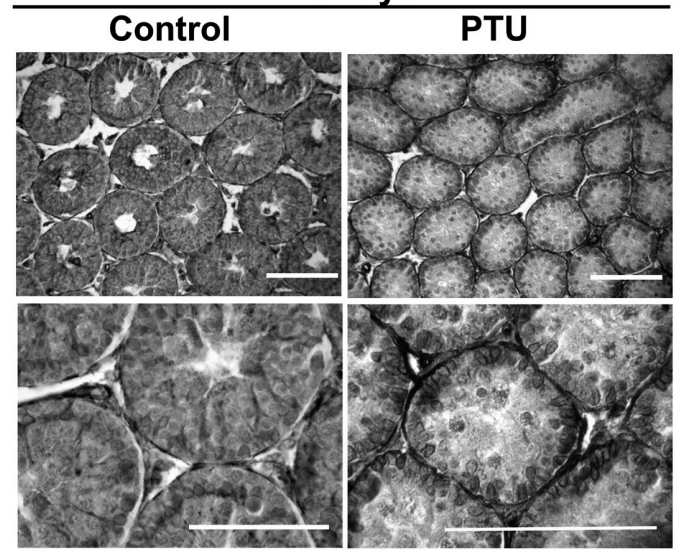

\section{5 days}

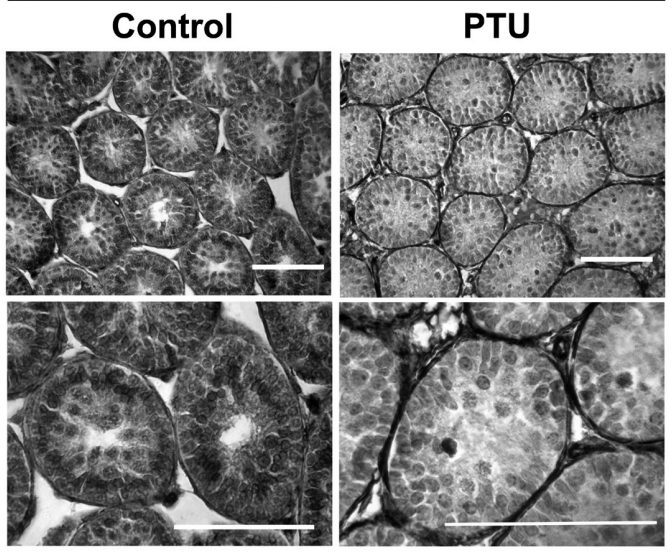

35 days

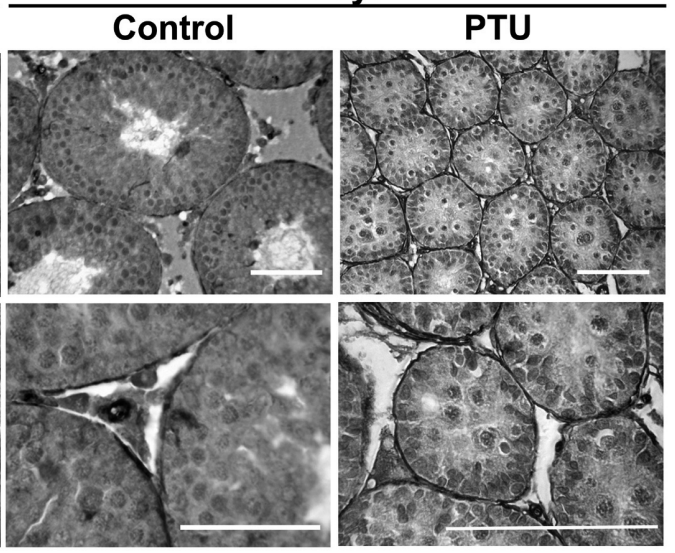

Figure 3: Immunolocalization of clusterin in control and PTU-treated pubertal rat testes. Testes slides from 15, 25 and 35-day-old rats stained with an antibody against clusterin. Observe how the Sertoli cells display a clear expression of clusterin in 15-day-old controls but not after PTU treatment. Clusterin expression changed from nuclear to cytoplasmic in controls, but remained nuclear in PTU-treated rats. The lower row shows a magnified image from the upper row. The first column at the left side shows a negative control. Bars represent $100 \mathrm{~mm}$. 
A
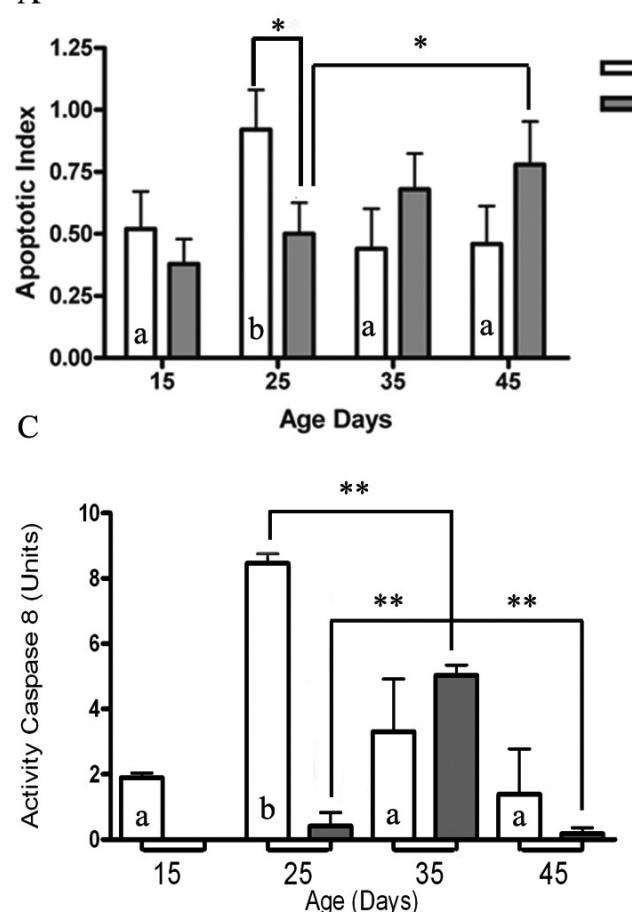

B
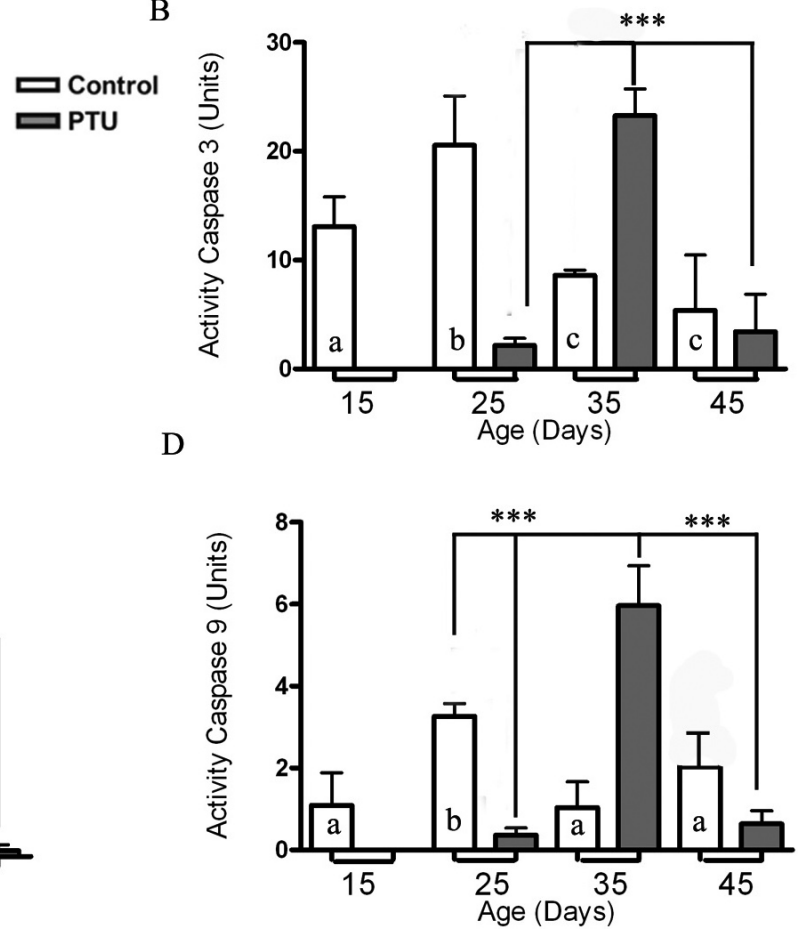

Figure 4: Delay of germ cell apoptosis with PTU-induced hypothyroidism. A) Testes from control and PTU-treated rats at different ages were fixed and the number of germ cells in apoptosis evaluated. The graph shows that the highest apoptotic index in control rats was at 25 days old. On the contrary, the apoptotic index in PTU-treated rats was significantly higher in 45-day-old rats. Seminiferous tubules from control and PTU-treated rats were isolated and the activity of caspase 3(B), caspase 8 (C) and caspase 9 (D) was evaluated at different ages. The graphs show that the highest activity of each caspase in PTU-treated rats was at 35 days, contrasting to controls where the activity peaked at 25 days. Bars represent the mean \pm S.D. (standard deviation) of three independent animals, each one with three replicas $\left(\mathrm{n}=3,{ }^{*} \mathrm{p}<0.05 ;{ }^{* *} \mathrm{p}<0.01 ;{ }^{* * *} \mathrm{p}<0.001\right)$. Different letters in the bars indicate a statistical difference between different ages under the same experimental conditions (control or PTU).

However, the maximum activity of caspases in PTU-treated rats was found to be in 35-day-old rats (Fig 4B, C, D, gray bars). Caspase activity returned to low levels in 45-day-old animals, similar to those found in control rats. Interestingly, control and PTU-treated rats showed caspase-3 activity levels similar under both conditions (Fig 4B). However, caspase-8 activity in PTU-treated animals was significantly lower than in control rats (Fig 4C, ${ }^{* *} \mathrm{p}<0.01$ ), while the opposite was found for caspase-9 activity (Fig $4 \mathrm{D},{ }^{* *} \mathrm{p}<0.01$ ). These results suggest that, despite the increase in caspase activation in 35-day-old rats, apoptosis in the treated testes is related to the intrinsic pathway, rather than to the extrinsic pathway of apoptosis, as is observed in control animals.

Since caspase activation suggested a contribution of the intrinsic pathway in PTU-induced germ cell apoptosis, we decided to study the expression of some proapoptotic genes involved in this process: p53, BAX and BAD. We found that p53 and BAX mRNA levels appeared similar in control and PTU-treated rat testes at all studied ages (Fig 5). p53 mRNA levels peaked in rat testes of 35 days old, whereas the levels of BAX mRNA peaked in 25-day-old rats, regardless of their experimental condition. The level of BAX mRNA of PTU-treated 25-day-old rats was lower than control rats at all studied ages, but this difference was not statistically significant (Fig 5B). BAD mRNA levels were similar in both groups, except in 25 and 45-day-old rats where we found that PTU-treated rats had significantly lower levels of BAD mRNA than control animals (Fig 5C, ${ }^{* *} \mathrm{p}<0.01$ ). On the contrary, 35-day-old rats showed that $\mathrm{BAD}$ levels were higher in PTU-treated rats, but this difference was not statistically significant (Fig 5C).

Thus, apoptotic index, caspase activity and mRNA levels of proapoptotic genes suggest a delay of germ cell apoptosis in PTU-treated rats.

\section{Discussion}

Here we have confirmed previous results showing that neonatal PTU-treated rats have a lower body weight, along with smaller testes and reduced diameter of seminiferous tubules, along with retardation of germ cell differentiation (Cook et al., 2005; De Franca et al., 1995; Holsberger and Cooke, 2005; Plotton et al., 2005). In addition, we have confirmed that there is a delay in the appearance of Sertoli cell differentiation markers, such as clusterin, related to retardation in Sertoli cell differentiation. An interesting finding is that the localization of clusterin in 25 through 45-day-old PTU-treated rats was similar to that found in 15-day-old control rats indicating that the localization of this protein is similar to that found in undifferentiated Sertoli cells. There are two known clusterin protein isoforms generated in human cells, a nuclear and a secretory form, produced through alternative splicing (Shannan et al., 2006b). The nuclear form 
A
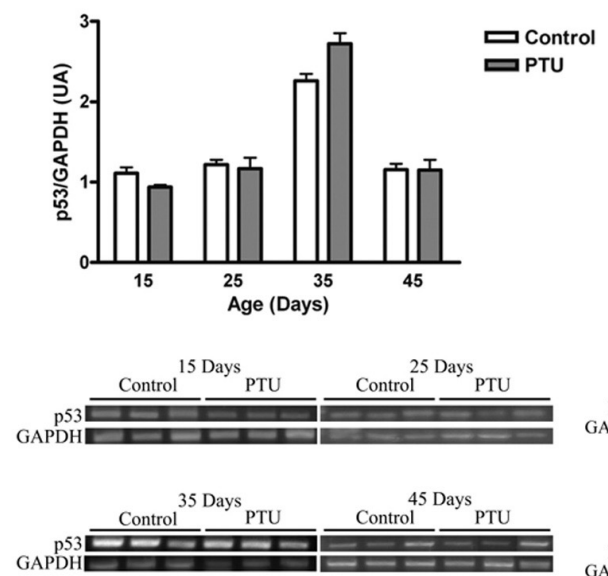

B
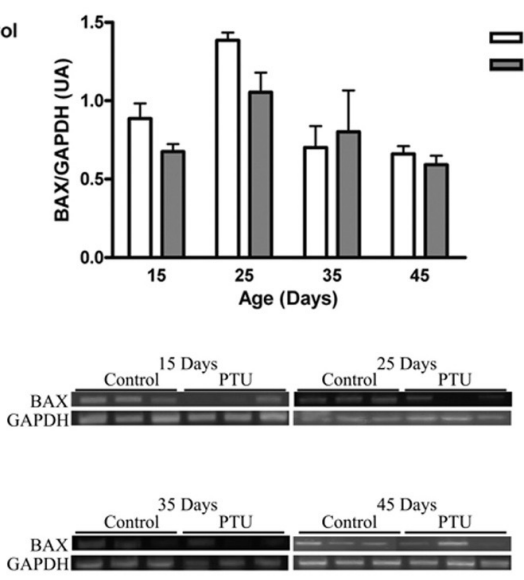
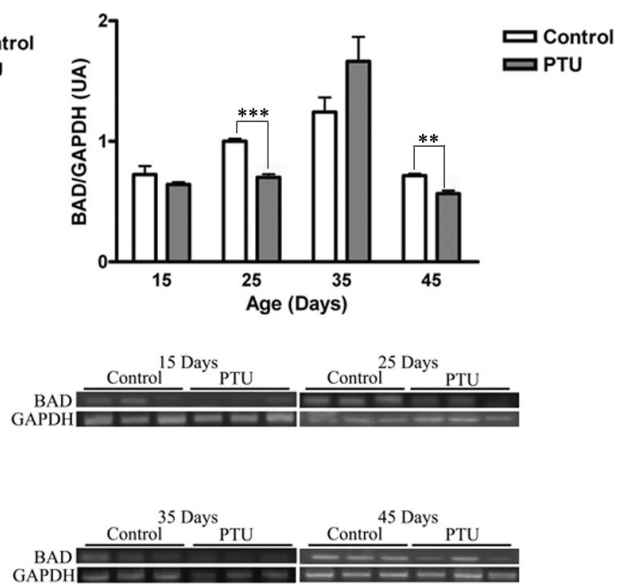

Figure 5: Gene expression patterns of apoptosis-related genes in PTU-treated rat testes.

The mRNA levels of (A) p53, (B) BAX and (C) BAD were measured at different ages and then quantified in relation to the housekeeping gene GADPH. Each lane represents a different sample from control or propylthiouracil (PTU)-treated rat testes. Bars represent the mean \pm $\mathrm{SD}$ of three independent experiments $(* * \mathrm{p}<0.01)$.

of clusterin has been associated with apoptosis and is possibly related to Sertoli cell function and the control of germ cell differentiation and apoptosis (Shannan et al., 2006a; Shannan et al., 2006b). Apoptosis of pachytene spermatocytes induced by methoxyacetic acid is preceded by an increase in clusterin, which is transferred from the Sertoli cell to germ cells (Clark et al., 1997). The abnormal localization of clusterin in Sertoli cells of PTU-treated animals could be related to a Sertoli cell failure, which is also related to the appearance of germ cell clusters in the tubule lumen, a common event caused by germ cell depletion due to Sertoli cell failure.

\section{Apoptosis in PTU-treated rats}

We showed here that germ cell apoptosis in PTU-treated rats correlated with an increase in the activities of caspases 3, 8 and 9, suggesting an active participation of these enzymes in this process. In this context, the individual contributions of each caspase seem to differ between PTU-treated and control animals. The levels reached by caspase- 8 and -9 were similar in PTU-treated animals, suggesting a similar contribution of the extrinsic and intrinsic pathway under these conditions. On the contrary, under physiological conditions (controls), only initiator caspase- 8 activity was significant increased during the first round of spermatogenesis, suggesting a major activation of the extrinsic pathway, which is similar to our previous results (Codelia et al., 2008; Lizama et al., 2007; Moreno et al., 2006). Thus, in terms of caspase activity, the apoptosis observed in PTU-treated rats is different from that observed under physiological conditions. In this context, it seems that hypothyroidism is similar to other models of hormone deprivation where the intrinsic apoptotic pathway plays a major role in germ cell demise as well (Ruwanpura et al., 2008; Sofikitis et al., 2008).

A major observation in this study was that the highest activity of caspases in PTU-treated animals was delayed by at least 10 days as compared to controls. It has been previously shown that the major cell type undergoing apoptosis during the first round of spermatogenesis is the pachytene spermatocyte (Jahnukainen et al., 2004; Lizama et al., 2007; Lizama et al., 2010; Moreno et al., 2006). We hypothesized that there was a major increase in the population of pachytene spermatocytes in more advanced ages in PTU-treated rats than in control animals. In fact, a delay in spermatocyte differentiation has already been described in this system (De Franca et al., 1995). Therefore, it seems reasonable to propose that the increase in caspase activity detected in 35-day-old PTU-treated rats is due to the pachytene spermatocytes undergoing apoptosis.

The kinetics of BAX and BAD expression during the first wave of spermatogenesis were not different between hypothyroid and control rats. Nonetheless, the expression levels of BAD were different between PTU and controls. The lower expression of BAD mRNA in 25-day-old PTU-treated rats could explain the low apoptosis levels observed at that age. Similarly, its elevated levels in 35-day-old rats could explain the increase in the apoptotic index at that age, along with caspase-9 activation. p53 and BAD mRNA showed elevated levels after the peak of apoptosis observed in control animals, which may be related to non-apoptotic function of these genes at this stage. In fact, BAD-deficient mice are fertile, and p53-deficient mice are sub-fertile, suggesting that their functions are not essential for spermatogenesis (Beumer et al., 1998; Ranger et al., 2003). Further studies are needed in order to determine which BCL-2 family genes are involved in germ cell apoptosis during hypothyroidism. Therefore, germ cell death in PTU-treated rats showed some characteristic of apoptosis, but the results suggest that the execution pattern is different to that observed from physiological conditions.

A further complication of induced hypothyroidism comes from the fact that thyroid hormone also stimulates Leydig cell differentiation, leading to a deficiency in testosterone production, also important in maintaining spermatogenesis. Follicle stimulating hormones (FSH), testosterone and growth factors provided by Sertoli cells behave as germ cell survival factors. In this context, PTU-induced hypothyroidism is 
an excellent model to study the role of this condition upon spermatogenesis, since all available data indicate that animals under these conditions have similar parameters to those undergoing hypothyroidism by spontaneous genetic alterations or dietary iodine deficiency (Crissman et al., 2000; Holsberger and Cooke, 2005; Holsberger et al., 2005b). The first wave of germ cell apoptosis seems to reflect the adjustment in the number of germ cells that can be maintained by Sertoli cells, which modulate the access to those growth factors. Therefore, it is logical that hormone deprivation causes important alterations in the first wave of germ cell apoptosis, but it does not necessarily mean that thyroid hormones act specifically on germ cells. Furthermore, the delay in apoptosis seems to be because of a retardation of the first wave and not because hypothyroidism affects apoptosis. In this way, it seems that the first wave of apoptosis is closely related to the formation and increase of pachytene spermatocytes, no matter the timing of their formation.

\section{ACKNOWLEDGMENTS}

This work was financed by a grant from the Chilean Research Council (FONDECYT 1070360) to RDM. Carlos Lizama is a fellow from CONICYT.

\section{REFERENCES}

BEUMER TL, ROEPERS-GAJADIEN HL, GADEMAN IS, VAN BUUL PP, GIL-GÓMEZ G, RUTGERS DH, DE ROOIJ DG (1998) The role of the tumor suppressor p53 in spermatogenesis. Cell Death Differ 5: 669-677.

BILLIG H, CHUN SY, EISENHAUER K, HSUEH AJ (1996) Gonadal cell apoptosis: hormone-regulated cell demise. Hum Reprod Update 2: 103117.

CLARK AM, MAGUIRE SM, GRISWOLD MD (1997) Accumulation of clusterin/sulfated glycoprotein-2 in degenerating pachytene spermatocytes of adult rats treated with methoxyacetic acid. Biol Reprod 57: 837-846.

CODELIA VA, CISTERNA M, ÁLVAREZ AR, MORENO RD (2010) p73 participates in male germ cells apoptosis induced by etoposide. Mol Hum Reprod 16: 734-742.

CODELIA VA, CISTERNAS P, MORENO RD (2008) Relevance of caspase activity during apoptosis in pubertal rat spermatogenesis. Mol Reprod Dev 75: 881-889.

COOK PS, HOLSBERGER DR, FRANCA LR (2005) Thyroid hormone regulation of Sertoli cell development. In: M. K. Skinner, M. D. Griswold, (Ed.), Sertoli cell Biology. London: Elsevier, pp. 217-226.

COOKE PS, HESS RA, PORCELLI J, MEISAMI E (1991) Increased sperm production in adult rats after transient neonatal hypothyroidism. Endocrinology 129: 244-248.

CRISSMAN JW, COOKE PS, HESS RA, MARTY MS, LIBERACKI AB (2000) Postulated human sperm count decline may involve historic elimination of juvenile iodine deficiency: a new hypothesis with experimental evidence in the rat. Toxicol Sci 53: 400-410.

DE FRANCA LR, HESS RA, COOKE PS, RUSSELL LD (1995) Neonatal hypothyroidism causes delayed Sertoli cell maturation in rats treated with propylthiouracil: evidence that the Sertoli cell controls testis growth. Anat Rec 242: 57-69.

HOLSBERGER DR, BUCHOLD GM, LEAL MC, KIESEWETTER SE, O'BRIEN DA, HESS RA, FRANCA LR, KIYOKAWA H, COOKE PS (2005a) Cell-cycle inhibitors p27Kip1 and p21Cip1 regulate murine Sertoli cell proliferation. Biol Reprod 72: 1429-1436.
HOLSBERGER DR, COOKE PS (2005) Understanding the role of thyroid hormone in Sertoli cell development: a mechanistic hypothesis. Cell Tissue Res 322: 133-140.

HOLSBERGER DR, JIRAWATNOTAI S, KIYOKAWA H, COOKE PS (2003) Thyroid hormone regulates the cell cycle inhibitor p27Kip1 in postnatal murine Sertoli cells. Endocrinology 144: 3732-3738.

HOLSBERGER DR, KIESEWETTER SE, COOKE PS (2005b) Regulation of neonatal Sertoli cell development by thyroid hormone receptor alpha1. Biol Reprod 73: 396-403.

JAHNUKAINEN K, CHRYSIS D, HOU M, PARVINEN M, EKSBORG S, SODER O (2004) Increased apoptosis occurring during the first wave of spermatogenesis is stage-specific and primarily affects midpachytene spermatocytes in the rat testis. Biol Reprod 70: 290-296.

LIZAMA C, ALFARO I, REYES JG, MORENO RD (2007) Up-regulation of CD95 (Apo-1/Fas) is associated with spermatocyte apoptosis during the first round of spermatogenesis in the rat. Apoptosis 12: 499-512.

LIZAMA C, ROJAS-BENÍTEZ D, ANTONELLI M, LUDWIG A, BUSTAMANTE-MARÍN X, BROUWER-VISSER J, MORENO RD (2010) TACE/ADAM17 is involved in germ cell apoptosis during rat spermatogenesis. Reproduction 140: 305-317.

MARAN RR, RAVICHANDRAN K, ARUNAKARAN J, ARULDHAS MM (2001) Impact of neonatal hypothyroidism on Leydig cell number, plasma, and testicular interstitial fluid sex steroids concentration. Endocr Res 27: 119-141.

MCKINNELL C, SHARPE RM (1997) Regulation of the secretion and synthesis of rat Sertoli cell SGP-1, SGP-2 and CP-2 by elongate spermatids. Int J Androl 20: 171-179.

MORENO RD, LIZAMA C, URZÚA N, VERGARA SP, REYES JG (2006) Caspase activation throughout the first wave of spermatogenesis in the rat. Cell Tissue Res 325: 533-540.

PETER ME, KRAMMER PH (2003) The CD95(APO-1/Fas) DISC and beyond. Cell Death Differ 10: 26-35.

PIETSCH EC, SYKES SM, MCMAHON SB, MURPHY ME (2008) The p53 family and programmed cell death. Oncogene 27: 6507-6521.

PLOTTON I, SÁNCHEZ P, PERRARD MH, DURAND P, LEJEUNE H (2005) Quantification of stem cell factor mRNA levels in the rat testis: usefulness of clusterin mRNA as a marker of the amount of mRNA of Sertoli cell origin in post pubertal rats. J Endocrinol 186: 131-143.

RANGER AM, ZHA J, HARADA H, DATTA SR, DANIAL NN, GILMORE AP, KUTOK JL, LE BEAU MM, GREENBERG ME, KORSMEYER SJ (2003) Bad-deficient mice develop diffuse large B cell lymphoma. Proc Natl Acad Sci U S A 100: 9324-9329.

RODRÍGUEZ I, ODY C, ARAKI K, GARCÍA I, VASSALLI P (1997) An early and massive wave of germinal cell apoptosis is required for the development of functional spermatogenesis. Embo J 16: 2262-2270.

RUWANPURA SM, MCLACHLAN RI, STANTON PG, MEACHEM SJ (2008) Follicle-stimulating hormone affects spermatogonial survival by regulating the intrinsic apoptotic pathway in adult rats. Biol Reprod 78: 705-713.

SHANNAN B, SEIFERT M, BOOTHMAN DA, TILGEN W, REICHRATH J (2006a) Clusterin and DNA repair: a new function in cancer for a key player in apoptosis and cell cycle control. J Mol Histol 37: 183-188.

SHANNAN B, SEIFERT M, LESKOV K, WILLIS J, BOOTHMAN D, TILGEN W, REICHRATH J (2006b) Challenge and promise: roles for clusterin in pathogenesis, progression and therapy of cancer. Cell Death Differ 13: 12-19.

SHARPE RM, (1994). The Physiology of Reproduction. New York: Raven Press.

SOFIKITIS N, GIOTITSAS N, TSOUNAPI P, BALTOGIANNIS D, GIANNAKIS D, PARDALIDIS N (2008) Hormonal regulation of spermatogenesis and spermiogenesis. J Steroid Biochem Mol Biol 109: 323-330.

SOKAL RR, (1995). Biometry: the principles and practice of statistic in biological research New York W. H. Freeman.

TAYLOR RC, CULLEN SP, MARTIN SJ (2008) Apoptosis: controlled demolition at the cellular level. Nat Rev Mol Cell Biol 9: 231-241.

YOULE RJ, STRASSER A (2008) The BCL-2 protein family: opposing activities that mediate cell death. Nat Rev Mol Cell Biol 9: 47-59. 